\title{
Maximum precipitation rates in the southern Blue Ridge Mountains of the southeastern United States
}

\author{
Charles E. Konrad II \\ Department of Geography, The University of North Carolina at Chapel Hill, Chapel Hill, North Carolina 27599-3220, USA
}

\begin{abstract}
Previous studies have identified relationships between annual precipitation and various attributes of the topography, such as elevation and exposure. Many hydrologic and geomorphic phenomena, however, are particularly sensitive to the manner in which the annual precipitation is delivered. Processes such as overland flow and erosion depend strongly on the maximum precipitation rate observed in a given precipitation event. In this study, relationships were identified between the maximum precipitation hourly rates observed in an event and selected topographic and geographic (TOPO/GEOG) attributes of the region. Rainfall events were identified from the hourly precipitation records at 44 stations in the Blue Ridge Mountains, USA, and classified according to the maximum rate of rainfall observed. The frequencies of low, moderate, and high intensity precipitation events were then statistically related to 30 TOPO/GEOG parameters. For the cool season, the strongest relationships were observed between low intensity events and several TOPO/GEOG attributes, especially northwest exposure. For the warm season, low and moderate intensity events exhibited strong relationships with elevation. High intensity events displayed weak to moderate relationships with the distance to the Gulf of Mexico and south exposure.
\end{abstract}

KEY WORDS: Orographic precipitation Precipitation rates - Blue Ridge Mountains

\section{INTRODUCTION}

The spatial patterns of precipitation in mountainous regions are quite complicated. It is well known that precipitation is enhanced on windward slopes during periods of moist, upslope flow and inhibited downstream on the leeward slopes. However, smaller scale features in the terrain locally modify the flow, inducing complex patterns of ascent/descent, thereby producing a more intricate spatial distribution of rainfall. For example, rising valleys in some some mountainous areas serve as conduits that channel moisture to local areas where strong uplift encourages higher precipitation rates (Lee \& Goodge 1984). Also, during the high sun period of the year, steep elevation gradients induce convective circulations that encourage thunderstorm development in favored areas of higher elevation (Banta \& Schaaf 1987)

Unfortunately, the spatial distribution of precipitation in many mountainous regions is not well documented as the network of rain gauges is particularly sparse. Therefore, initiatives (e.g. Tabios \& Salas 1985,
Hevesi et al. 1992, Phillips et al. 1992) have been taken to utilize interpolation schemes that provide better estimations of the spatial pattern of precipitation. Some of these techniques (e.g. cokriging) make use of a topographic variable, such as elevation, as an auxillary variable to aid in the determination of the spatial patterns of precipitation. Utilizing a digital elevation model (DEM) and point measurements of precipitation, Daly et al. (1994) developed an analytical model within a GIS (geographical information systems) environment that estimated precipitation on a regularly spaced grid. In particular, the model aggregated individual cells in the DEM into relatively homogenous macro-units exhibiting similar slope aspects. Regression techniques were then used to interpolate spatial patterns of precipitation within each macro-unit. Their model provided better estimates of precipitation compared to interpolations generated by various kriging techniques.

A host of other topographic parameters, besides elevation, have been used to explain the spatial distribition of precipitation. Basist et al. (1994), for example, 
derived statistical relationships between annual precipitation and elevation, slope, exposure, valley orientation, and various derivatives of these parameters. They found that the relationships varied markedly from one mountain range to another. In another study, Houghton (1979) utilized numerous topographic, geographic, and synoptic parameters to describe variations in monthly, seasonal, and annual precipitation in the Great Basin region of the western United States. He found that the relationships between these parameters and precipitation changed with the seasons.

Most precipitation studies in mountainous terrain have focused on annual precipitation totals. The relationships between precipitation and topography, however, depend strongly on the types and frequencies of precipitation events that are typically observed in mountainous areas as well as the season of the year (Houghton 1979, Konrad unpubl.). Various types of rainlall events are influenced strongly by the topography whereas other events are influenced little or not at all. Annual precipitation represents the integrated influence of all precipitation events that are observed during a given year, particularly those events that are heavy. If different event types have unique relationships with the topography, relationships derived between annual precipitation and the topography are weakened. Konrad (unpubl.) found this to be the case in the southern Blue Ridge Mountains, USA, the study area for this work. He demonstrated that the frequencies of light and heavy precipitation events display differing relationships with the topography. This in turn contributes to a weakening of the relationships between annual precipitation and the topography.

The challenges of ascertaining the spatial patterns in hourly precipitation rates over mountainous terrain are even more daunting. There are relatively few rain gauges that measure hourly rainfall rates in mountainous regions, at least in the United States. Also, the estimation of hourly precipitation rates is subject to measurement error (e.g. wind blown rain droplets or snow is only partially collected by the gauge). Obviously, hourly precipitation rates bear some relationship with the climate of the area, in particular, the moisture content of the atmosphere. This in turn can be related climatologically to the mean air temperature of an area (potential to hold water vapor) and the distance to the nearest moisture source. Thorpe \& Scott (1982), for example, found regional scale increases in the mean hourly precipitation rate southward across the northeastern United States (towards climatologically warmer areas that exhibit higher dew point temperatures). In mountainous regions, however, such relationships are not intuitively obvious. Moreover, processes such as soil erosion, infiltration, and overland flow are strongly related to the attributes of a given precipitation event, especially the hourly precipitation rate. These processes are certainly more significant in mountainous areas where the predominance of steep slopes promotes debris flows and flash flooding. A strong need exists, therefore, to identify relationships between hourly precipitation rates and topographic features in mountainous terrain.

In this study, statistical relationships are developed between event maximum precipitation rates and various attributes of the topography and geography in the southern Blue Ridge Mountains. Three precipitation event types are defined in this study based on the maximum precipitation rate observed during an event. Frequencies of each event type are tabulated for 44 stations within the Blue Ridge Mountains and statistically related to 30 topographic and geographic (TOPO/ GEOG) parameters shown in previous research efforts (e.g. Houghton 1979, Basist et al. 1994, Konrad unpubl.) to be related to precipitation.

\section{STUDY AREA}

The study area encompasses the southern Blue Ridge Mountains, which are found in portions of western North Carolina, eastern Tennessee, extreme northwest South Carolina, and extreme northern Georgia (Fig. 1). As shown in Fig. 2, most of the region lies above $600 \mathrm{~m}(2000 \mathrm{ft})$. Numerous peaks in the core of the Blue Ridge Mountains exceed $1500 \mathrm{~m}$ (5000 ft). The interior portion of the mountain range is dissected by deep valleys associated with westward flowing tributaries of the Tennessee River. The southeastern limits of the mountains are largely defined by an escarpment that is cut sharply by southeastward flowing streams that drain into the Atlantic Ocean. The Piedmont lies to the southeast of the Blue Ridge Mountains, and consists of a gently rolling upland with elevations generally less than $300 \mathrm{~m}$ (1000 ft). The Tennessee River valley, a region of broad valleys and relatively low ridges, lies west of the area.

Since the mountains are highly exposed to moist flow from the Gulf of Mexico, much of the region receives high annual precipitation totals (Konrad unpubl.). The terrain, however, strongly modulates precipitation amounts locally. Numerous mountains in the southern portion of the study area receive over $2000 \mathrm{~mm}$ of annual precipitation whereas many of the highly sheltered valleys within the mountains receive less than $1000 \mathrm{~mm}$. A small proportion of the annual precipitation falls in the form of snow during the winter. Some of the higher peaks in the northern portion of the study area receive over $800 \mathrm{~mm}$ of snow annually on average while locales in the valleys typically receive less than $200 \mathrm{~mm}$. 


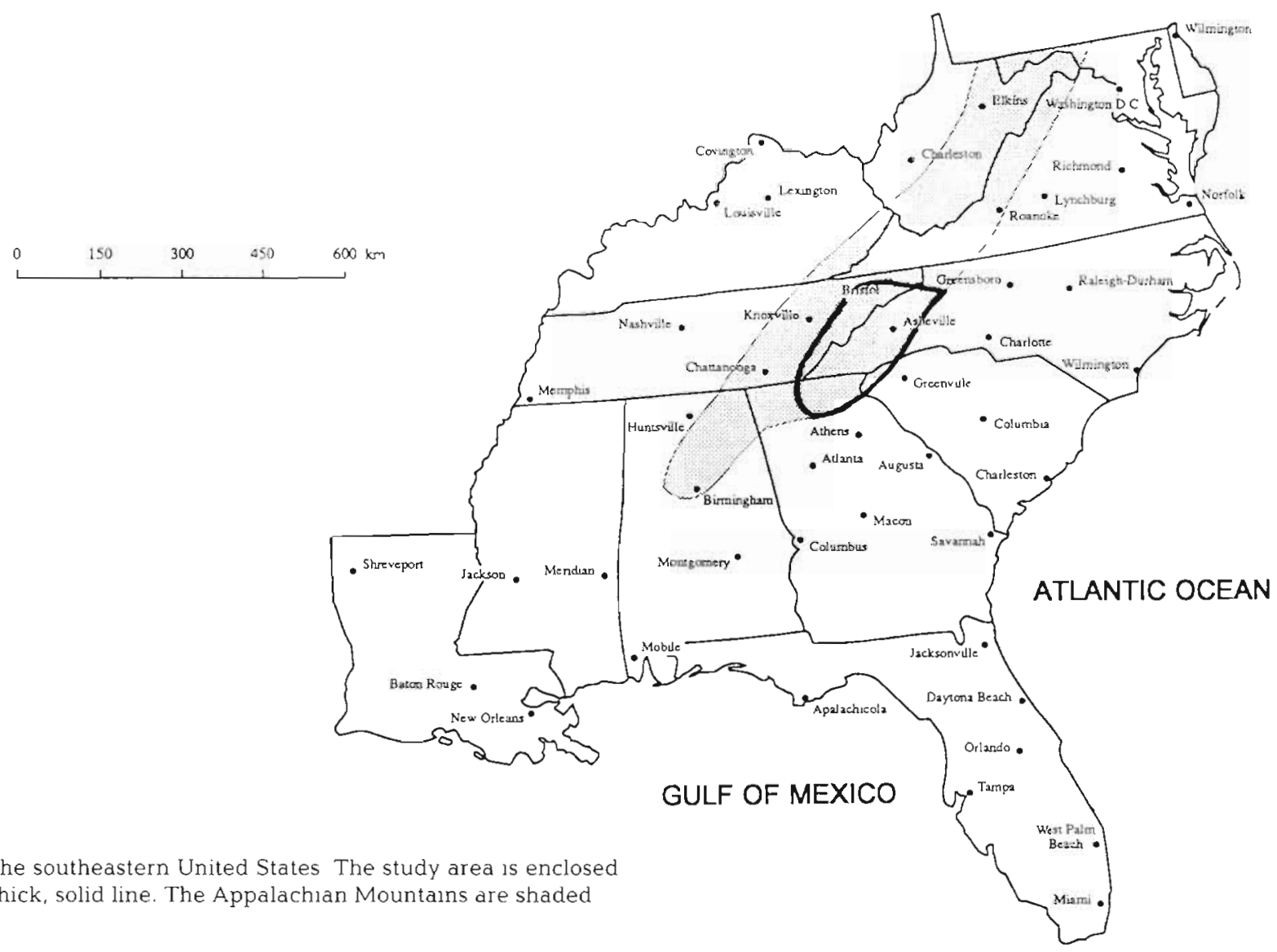

Fig. 1. The southeastern United States The study area is enclosed by a thick, solid line. The Appalachıan Mountanns are shaded

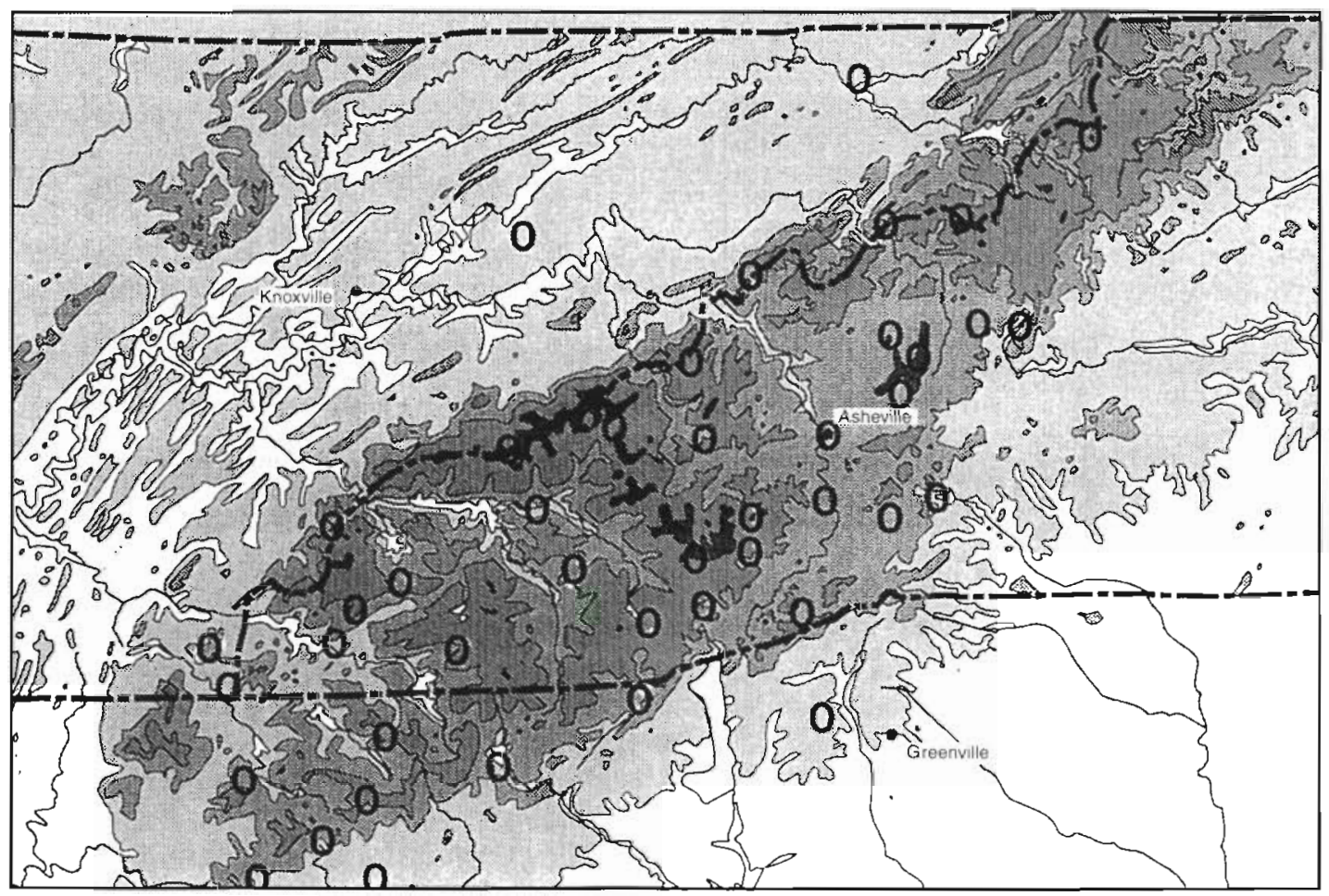

Fig. 2. Close up of the study area depıcting the broad scale topographic features HPD sites are indicated by open circles. $1000 \mathrm{ft}=300 \mathrm{~m}$ 


\section{DATA AND METHODOLOGY}

Records from the National Climate Data Center data set Hourly Precipitation Data (HPD) (Hatch 1983) were obtained for 44 stations within the study area (Fig. 2). These stations were selected because they had reasonably complete records (greater than $85 \%$ coverage), and they provided a good representation of the range of topographic situations within the study area. In areas of good HPD coverage, stations with records exceeding $20 \mathrm{yr}$ were utilized; however, in most of the areas of high elevation, long term HPD data were not available. Therefore, HPD sites with record lengths, in many cases, of only 8 yr were utilized. Because of the record shortness, the frequencies of unusual events (i.e. events displaying longer return intervals) may be poorly estimated. All of these stations, however, had relatively complete records (at least $88 \%$ complete) over the same time period (1948 to 1955).

Definition and classification of precipitation events. A precipitation event (Robinson \& Henderson 1992) was defined in this study as a period of recorded rainfall in which breaks in the precipitation do not exceed $1 \mathrm{~h}$. Thus, 2 separate precipitation events must be separated by at least a $2 \mathrm{~h}$ dry interval. Such a separation interval is desirable since it allows for small breaks in a continuous event yet does not merge events that are clearly separate. In the development of a precipitation event climatology, it is necessary to accurately estimate the record length (i.e. the period in which the station is on-line and recording precipitation events). If precipitation was not reported for $28 \mathrm{~d}$ or more at a given station, it was assumed that station was not recording precipitation, and the estimations of record length were reduced accordingly. This assumption is reasonable given that $28 \mathrm{~d}$ of dry weather is extremely unusual in this region.

Separate precipitation event climatologies were developed for the cool (1 October to $31 \mathrm{March}$ ) and the warm seasons (1 April to 30 September). Since seasonal changes are observed in the suite of mechanisms responsible for the precipitation, it is useful to partition the climatology into a cool season in which frontal overrunning and orographic uplift are the predominant precipitation mechanisms, and a warm season in which convective circulations exert a strong control on precipitation (Banta 1984).

Precipitation rates may be defined several different ways. Thorpe \& Scott (1982), for example, calculated an average hourly precipitation rate for the summer and winter months based on hourly precipitation amounts from all events occurring over several seasons. Average precipitation rates should be viewed with caution, however, because they are weighted strongly towards the numerous hours in which low hourly precipitation rates are typically observed. The hydrologic and geomorphic impacts of precipitation are greatest during the hour in which the precipitation is heaviest. Therefore in this study, each precipitation event was assigned to an intensity class based on the maximum hourly precipitation rate observed during the event. Three intensity classes were distinguished in this work based on the maximum hourly rate: light, 2.54 to $6.35 \mathrm{~mm} \mathrm{~h}^{-1}$; moderate, 6.36 to $12.70 \mathrm{~mm} \mathrm{~h}^{-1}$; heavy, $>12.70 \mathrm{~mm} \mathrm{~h}^{-1}$. Mean seasonal frequencies for the 3 event classes were calculated for each HPD station.

Topographic and geographic parameters. The topographic attributes and geographic position of each HPD station were quantified by utilizing topographic maps (primarily at the scale of $1: 200000$ ) to estimate the values of various TOPO/GEOG parameters defined below:

Mean elevation. Calculated within a $10 \times 10 \mathrm{~km}$ grid centered over the HPD station. Computations of mean elevation provide a measure of the influence of the 'smoothed topography' on precipitation variations. Pedgley (1970) and others have used mean elevations to assess the role of the larger scale or gross topographic features in influencing precipitation patterns. In their work, for example, deep valleys in complex terrain were found in some cases to exhibit precipitation totals similar to those found on the surrounding mountains.

The remaining topographic parameters were calculated with respect to varying vector directions (east, southeast, south, southwest, west, and northwest). An analysis of the different synoptic situations in which precipitation is observed in the Blue Ridge Mountains revealed that moisture advection may occur from any of these directions while the occurrence of moisture advection from the north or northeast is rare (Konrad unpubl.). The calculation of multidirectional topographic parameters is useful; for example, Konrad (unpubl.) found that the strength of the relationship between precipitation and a topographic attribute varies according to the direction in which the topographic attribute is calculated. Hence, a direction can be found that maximizes the relationship between the two. Most previous studies assumed moisture transport from the direction of the prevailing wind and, therefore, calculated topographic parameters from this vector direction. The following 4 topographic attributes are considered from a multidirectional perspective:

Valley orientation. The difference in degrees or directional offset between each vector direction defined above and the orientation of the watershed or valley containing the $\mathrm{HPD}$ station. This variable takes into the account the occurrence of orographic precipitation enhancement due to the funnelling of moist winds up a mountain stream valley.

Slope. A parameter that defines the elevation offset between the HPD site and a point $5 \mathrm{~km}$ away in each 
vector direction. This topographic variable serves as an indicator of the orographic ascent or descent rate from various wind vector directions and, hence, tests the degree to which the slope may be associated with the occurrence of events with various precipitation rates.

Exposure. A parameter that specifies the distance to an upwind mountain barrier that is $150 \mathrm{~m}$ higher than the HPD site. In cases where mountain barriers are found more than $100 \mathrm{~km}$ away, the exposure is assigned a maximum value of $100 \mathrm{~km}$.

Elevation $x$ Exposure. A parameter that takes into account the combined effects of elevation and exposure. Spatial patterns of precipitation can be influenced strongly by the interaction of these 2 parameters (Houghton 1979).

Four parameters were utilized to specify the position of the HPD location with respect to moisture source regions and the southeastern edge of the Blue Ridge Mountains (i.e. the Blue Ridge Front).

Distance to moisture source. Minimum distance from the HPD location to the Gulf of Mexico and Atlantic Coasts.

Distance to the point of maximal exposure. The distance to the Blue Ridge Front along a direct trajectory from the HPD station to the nearest Gulf of Mexico and Atlantic Ocean coastline. The Blue Ridge Front defines the set of points, generally along the southeast edge of the mountains, that display the greatest exposure to the moisture source regions.

Correlation and regression analyses. The TOPO/ GEOG parameters described above were calculated for each of the $44 \mathrm{HPD}$ sites and statistically related to the seasonal frequencies of low, moderate, and high intensity precipitation events. To find significant relationships, a correlation matrix was developed between the TOPO/GEOG parameters and all of the precipitation event classes.

Utilizing the TOPO/GEOG parameters as independent variables (predictors), a stepwise regression analysis was then undertaken to develop a regression model that explains the variance in the frequency of precipitation events for each intensity class. A stepwise routine attempts to find the 'best' predictor model of the dependent variable (event frequencies). This is carried out by first adding variables to the model that exhibit the most predictive power. Additional predictor variables are added as long as they provide a significant contribution to the model. Variables that have been added to the model are removed if they no longer make a significant contribution after the addition of new variables. SAS Institute Inc (1988) provides more information on this procedure. Only predictor variables with regression slopes (beta values) statistically significant at the 0.95 level were employed in the model.

\section{RESULTS}

\section{Cool season precipitation events}

The frequencies of low intensity precipitation events for the cool season are significantly correlated with numerous TOPO/GEOG parameters as shown in Fig. 3. Low intensity events are most strongly associated with the distance to the Gulf of Mexico (i.e. more events with increasing distance from the Gulf Coast). Northwest exposure, slope, and elevation also show relatively strong relationships with low intensity events. The frequencies of moderate intensity events are most strongly related to elevation and south slope. The correlations between moderate intensity events and the TOPO/GEOG parameters, however, are generally weaker and not as numerous. High intensity events show significant correlations with only 4 TOPO/GEOG parameters. These events are most strongly associated with the distance to the Gulf (more high intensity events with decreasing distance to the Gulf Coast) and south exposure.

A stepwise regression was performed using the TOPO/GEOG variables as independent variables to explain spatial variations in precipitation event frequencies. Regression equations were developed for the 3 precipitation intensity classes as shown in Table 1. Spatial variations in the frequencies of low intensity events are explained fairly well by the regression equation. The explanatory power of the equations describing spatial variations in the moderate and high intensity events, however, declines markedly.

\section{Warm season precipitation events}

Correlations between the frequencies of the 3 warm season event types and the TOPO/GEOG parameters are presented in Fig. 4. The frequencies of low and moderate intensity events are most strongly associated with elevation and mean elevation, respectively. The low intensity events exhibit a moderate correlation with northwest slope and exposure, while moderate intensity events display a similar correlation with south facing slopes. High intensity events display significant but weak correlations with elevation, southwest exposure, and south slope.

The correlation patterns observed between the cool and warm events are quite similar although there are some intriguing differences. The correlations connected with warm season, moderate intensity events, for example, are generally stronger, especially in the case of elevation, a variable that appears to be more important in warm season events. The GEOG parameters, on the other hand, show stronger relationships with the cool 
NORTHWEST

\begin{tabular}{|ll|}
\hline exp $\times$ elevation & -.32 \\
\hline \hline slope & .33 \\
exposure & .30 \\
\hline & \\
\hline exposure & .65 \\
slope & .59 \\
valley orientation & .50 \\
\hline
\end{tabular}

\section{WEST}

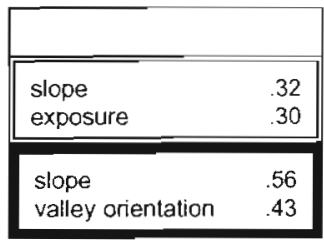

SOUTHWEST

\begin{tabular}{|ll|}
\hline exposure & 30 \\
\hline \hline slope & .41 \\
exp. $\times$ elevation & .35 \\
\hline slope & \\
exp. $\times$ elevation & .48 \\
\end{tabular}

\section{GULF OF MEXICO}

\begin{tabular}{|ll|}
\hline total distance & -.47 \\
\hline \hline & \\
\hline min. distance & .58 \\
total distance & .67 \\
\hline
\end{tabular}

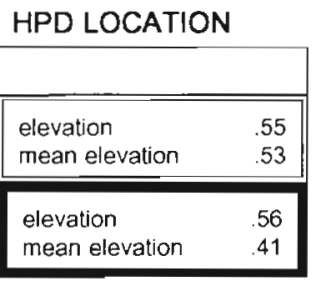

SOUTH

\begin{tabular}{|ll|}
\hline exposure & .40 \\
\hline \hline slope & .42 \\
exp. $\times$ elevation & .37 \\
exposure & .36 \\
\hline slope & .37 \\
exp. x elevation & .34 \\
valley orientation & -.46 \\
\hline
\end{tabular}

SOUTHEAST

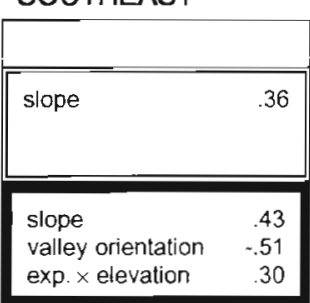

ATLANTIC OCEAN

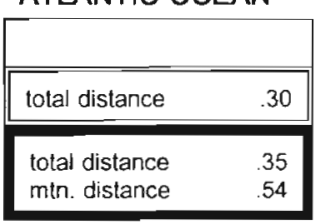

Fig. 3. Schematic diagram portraying correlation patterns between each cool season precipitation class and the TOPO/GEOG variables. Boxes provide correlations with TOPO parameters along indicated vector directions and correlations with GEOG parameters, which relate to distances to given moisture source coastlines. Each box is divided into a bottom (thick border). middle (double border), and upper (single border) section that provide correlations with low, moderate, and high intensity event frequencies, respectively. All indicated correlations are significant at the 0.05 level or higher Note that $\mathrm{mtn}$. distance and total distance refer to the distance to the point of maximal exposure along the mountain front and the distance to the moisture source, respectively. exp.: exposure

season events, especially the low and high intensity events. Only light events during the warm season show significant relationships with the GEOG variables.
Regression equations developed to explain the variance in the frequencies of the 3 types of warm season precipitation events are shown in Table 2 . The spatial variations in the low intensity events are explained best by the regression model. Variations in the frequencies of moderate events are also explained relatively well. The model does a poor job, however, of explaining variations in the frequency of high intensity events, which are apparently not strongly connected with any of the topographic or geographic attributes of the area.

\section{DISCUSSION}

Low intensity events are most strongly correlated with increasing distances to the Gulf of Mexico and northwest exposure during the cool season. Many of these events may be associated with the frequent occurrence of cyclonic systems that move over and north of the area (Zishka \& Smith 1980). The westerly winds to the south of these systems promote orographic uplift in local areas highly exposed to the northwest. Areas more distant from the Gulf of Mexico (northern portion of study area) are either closer to, or more frequently in the path of, these cyclonic systems and, therefore, receive low intensity precipitation more frequently. The low precipitation rates in these events may be connected with the relative dryness of the continental air advected by the westerly winds.

Warm season, low intensity events exhibit similar correlation patterns; however, in this case, elevation is most strongly tied to the spatial variations in the frequency of these events. The results of this work suggest that orographically

Table 1. Regression equations that predict the cool season frequencies of low, moderate, and high intensity precipitation events in the southern Blue Ridge Mountains

\begin{tabular}{lrll}
\hline Intensity & Regression equation & $\mathrm{R}^{2}$ \\
\hline High & $16.0417-0.01516$ East slope -0.01947 Gulf distance +0.00002233 SE exposure $\times$ Elevation & 0.42 \\
Moderate & $30.4358+0.0102137$ Mean elevation -0.02827 Gulf distance +0.00003715 E exposure $\times$ Elevation & 0.58 \\
Low & $-48.0718+0.1033$ Gulf distance +0.1108 Atlantic distance +0.000082 NW exposure $\times$ Elevation & 0.76 \\
\hline
\end{tabular}


induced convection is responsible for many of the low intensity events. Areas of high elevation serve as elevated heat sources during the high sun season (see Banta 1984); hence, they promote convection and precipitation locally in these areas. Orographic uplift may contribute as well, forcing air parcels to an altitude where conditional instability may be released. Moderate intensity events also show a strong relationship with elevation; thus, convection associated with the orographically forced heat island may be responsible for these events as well.

High intensity events are not strongly associated with any of the topographic or geographic attributes investigated in this study. During the cool season, however, these events do show a correspondence with the proximity to the Gulf of Mexico and south exposure. Relationships with these TOPO/GEOG parameters suggest that moisture bearing southerly winds from the Gulf of Mexico are responsible for these events. Evidence for this is provided by Konrad (1995), who demonstrated through a trajectory analysis that numerous heavy rain events in the Appalachian Mountains are associated with lower tropospheric transports of moisture directly from the Gulf of Mexico or the Atlantic Ocean.

Substantial seasonal variations are noted in the mean frequency of the 3 event types as shown in Table 3 . These variations are especially noted in the contribution each makes to the total seasonal precipitation. For example, low intensity events contribute the greatest to the cool season precipitation totals, but high intensity events contribute the most to the warm season totals. These differences underscore the importance of partitioning relation-
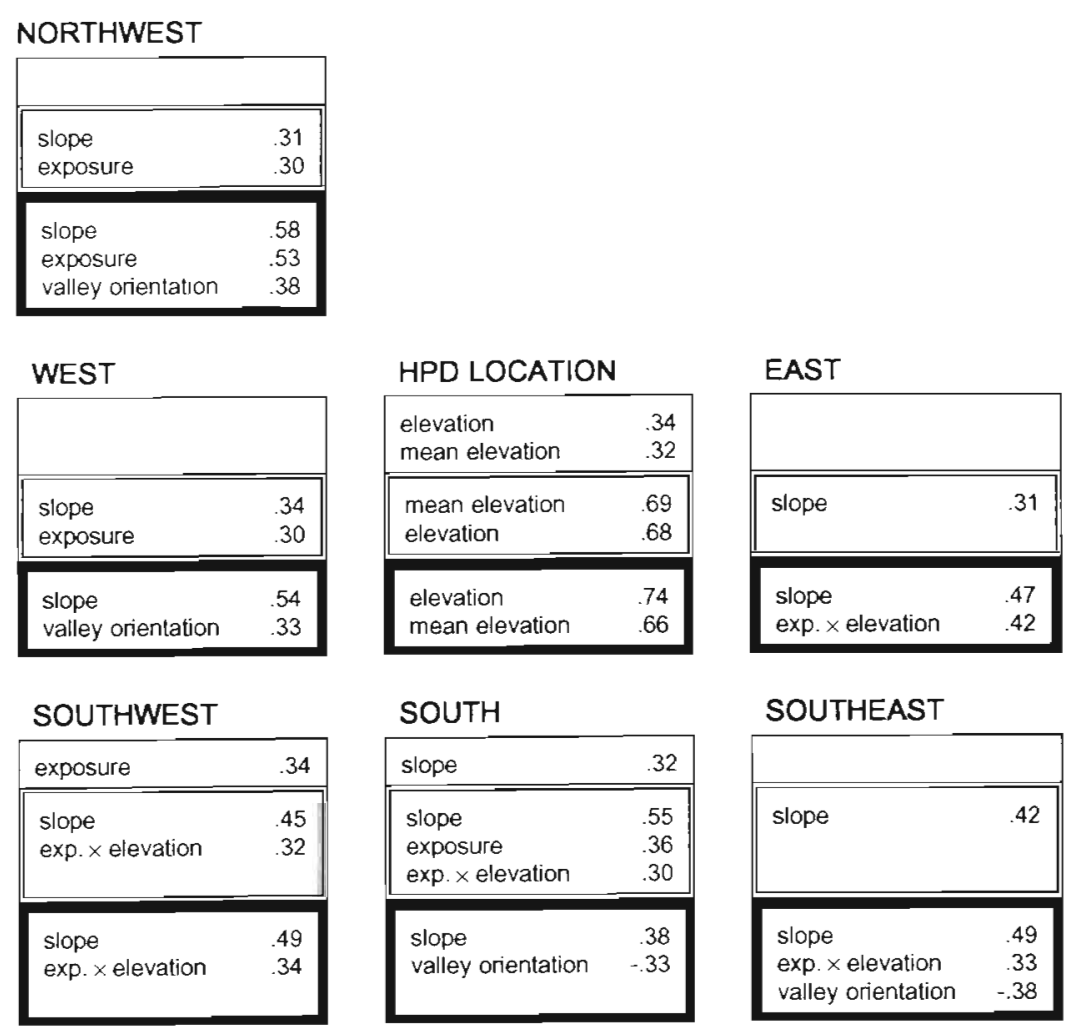

SOUTHEAST
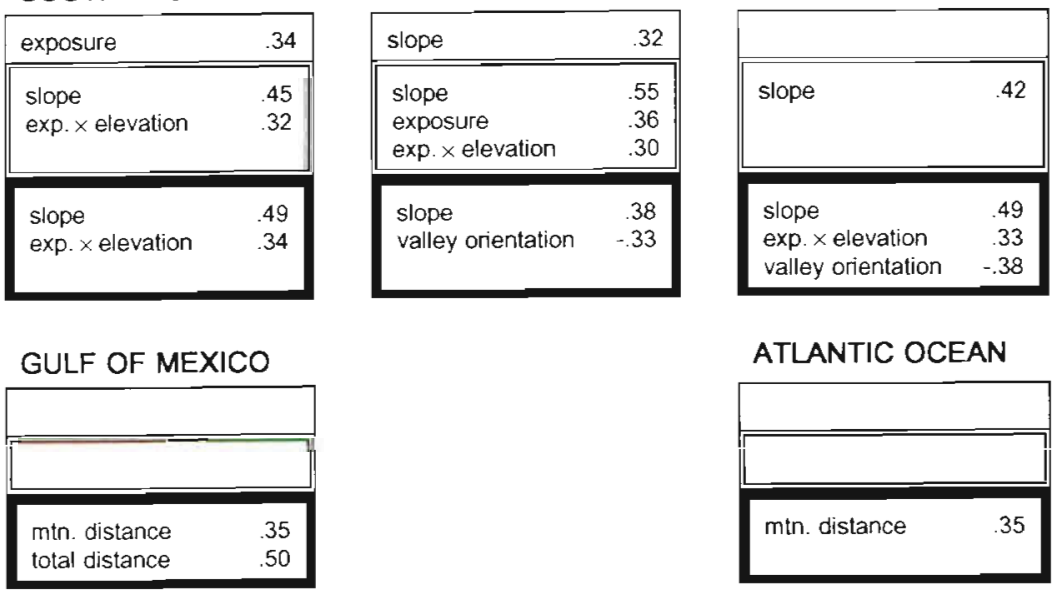

ATLANTIC OCEAN

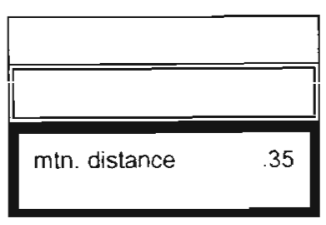

Fig. 4. Same as Fig. 3 except for the warm season: schematic diagram portraying correlation patterns between each precipitation class and the TOPO/GEOG variables. See the legend of Fig. 3 for further details

ships between precipitation rates and the topography by season.

A comparision of the coefficients of variation (Table 3) reveals that high intensity events display the greatest spatial variation. Unfortunately, this spatial variation is not well accounted for by the TOPO/GEOG parameters, especially during the summer when these

Table 2. Regression equations that predict the warm season frequencies of low, moderate, and high intensity precipitation events in the southern Blue Ridge Mountains

\begin{tabular}{|lrl|}
\hline Intensity & Regression equation & $\mathrm{R}^{2}$ \\
\hline High & $8.5159+0.00001785 \mathrm{SW}$ exposure $\times$ Elevation & 0.19 \\
Moderate & $11.1907+0.009830$ Mean elevation +0.0000281 SE Exposure $\times$ Elevation & 0.57 \\
Low & $7.1793+0.01704$ Elevation -0.04660 South slope +0.03430 Gulf distance & 0.69 \\
\hline
\end{tabular}


Table 3. Cool season and warm season precipitation event frequencies averaged for all HPD stations. CV: coefficient of variation

\begin{tabular}{|lrrrc|}
\hline Intensity class & $\begin{array}{c}\text { Mean } \\
\text { frequency }\end{array}$ & SD & CV & $\begin{array}{c}\text { \% of total } \\
\text { seasonal } \\
\text { precip. }\end{array}$ \\
\hline Cool season & & & & \\
High & 2.4 & 1.44 & 58.7 & 14.4 \\
Moderate & 10.5 & 2.88 & 27.4 & 36.1 \\
Low & 27.7 & 7.01 & 25.3 & 37.2 \\
Warm season & & & & \\
High & 5.9 & 1.11 & 29.7 & 33.9 \\
Moderate & 10.7 & 2.24 & 20.9 & 30.8 \\
Low & 21.9 & 4.26 & 19.4 & 26.3 \\
\hline
\end{tabular}

events are most common. It is these events that deserve the greatest attention since they are responsible for the greatest geomorphic alterations. Certainly it is possible that the topography does not exert a strong influence on the development of these events. However, the short record length of nearly half of the HPD stations ( 8 yr) in the study may act to decrease the strength of the relationship. Because the high intensity events are not that common, especially in the winter, a longer record length may be necessary to accurately capture the seasonal frequencies of these events.

As mentioned earlier, the density of the daily precipitation network in the study area is greater than that found in the HPD network. Additionally, many of these daily stations have longer records. It is quite possible that these records can be utilized to more accurately predict the spatial pattern of hourly precipitation intensities. To carry this out, relationships need to be identified between daily precipitation totals and the maximum hourly precipitation rate during an event. If these relationships exist, they can be used to transform the records of daily precipitation totals into a precipitation rate climatology that is more robust and reflects a greater density of recording stations across the region. Such a climatology would aid in the development of stronger relationships between high precipitation rates and topographic features. This approach would obviously require accounting for the factors that influence precipitation rates, including seasonality and synoptic regimes.

To better specify the spatial patterns of precipitation intensity, the approach utilized in this work may be applied within the framework of a geographic information system (GIS). In particular, the TOPO/GEOG variables can be readily calculated at each point or pixel of a digital elevation model (DEM) and related to the point precipitation data to develop stronger relation-

Editor: V. Meentemeyer, Athens, Georgia, USA ships between precipitation rates and the topography. The application of these regression relationships at the pixel level will provide a finer scale spatial pattern of precipitation intensities that more accurately reflects the influences of the topography.

Acknowlegements. The author thanks Bill Sea and Lihua Geng for their help processing the HPD data and Patty Neumann for her assistance in the development of the topographic map.

\section{LITERATURE CITED}

Banta RM (1984) Daytime boundary-layer evolution over mountainous terrain. Part I: Observations of the dry circulations. Mon Weather Rev 112:340-356

Banta RM, Schaaf CB (1.987) Thunderstorm genesis zones in the Colorado Rocky Mountains as determined by traceback of geosynchronous satellite images. Mon Weather Rev i 1 15:463-476

Basist A, Bell GD, Meentemeyer V (1994) Statistical relationships between topography and precipitation patterns. J Clim 7:1.305-1315

Daly C, Neilson RP, Phillips DL (1994) A statistical-topographic model for mapping climatological precipitation over mountainous terrain. J appl Meteorol 33:140-158

Hatch WL (1983) Selective guide to climatic data sources. Key to meteorological records documentation 4.11 National Climate Data Center, Asheville, NC

Hevesi JA, Istok JD, Flint AL (1992) Precipitation estimation in mountaınous terrain using multivariate geostatistics. Part I: Structural analysis. J appl Meteorol 31:661-688

Houghton JG (1979) A model for orographic precipitation in the north-central Great Basin. Mon Weather Rev 1.07: 1462-1475

Konrad CE (1995) Moisture trajectories associated with heavy rainfall in the Appalachian region of the United States. Phys Geogr 15:227-248

Lee LG, Goodge GW (1984) Meteorological analysis of an intense 'east slope' rainstorm in the southern Appalachians. In: Tenth Conference on Weather Forecasting and Analysis. American Meteorological Society, Boston

Pedgley DE (1970) Heavy rainfalls over Snowdonia. Weather 25:340-349

Phillips DL, Dolph J, Marks D (1992) A comparison of geostatistical procedures for the spatial analysis of precipitation in mountainous terrain. Agricult For Meteorol 58:119-1.41

Robinson PJ, Henderson KG (1992) Precipitation events in the south-east USA. Int J Climatol 12:701-720

SAS Institute Inc (1988) SAS users guide: version 6.03. SAS Institute Inc, Cary, NC

Tabios GQ, Salas JD (1985) A comparative analysis of techniques for spatial interpolation of precipitation. Wat Resour Bull 21:365-380

Thorpe JM, Scott BC (1982) Preliminary calculations of average storm duration and seasonal precipitation rates for the northeast sector of the United States. Atmos Environ 16:1763-1774

Zishka KM. Smith PJ (1980) The climatology of cyclones and anticyclones over North America and surrounding ocean environs for January and July, 1950-77. Mon Weather Rev 108:387-401

Manuscript first received: August 17, 1994

Revised version accepted: December 20, 1994 